\title{
ENCANTAR: ENCONTRO DE BIBLIOTECAS, LEITURA E CONTAÇÃO DE HISTÓRIAS
}

\author{
ENCANTAR: MEETING OF LIBRARIES, \\ READING AND STORY TELLING
}

\author{
Susyleide Gomes de Brito ${ }^{1}$, Maria Marinês Gomes Vidal ${ }^{2}$, \\ Karyna da Rocha Tavares ${ }^{3}$, Shirly Pimentel Vieira ${ }^{4}$
}

RESUMO: Relata a experiência do projeto Encantar - Encontro de Bibliotecas, Leitura e Contação de Histórias, da Divisão de Apoio ao Usuário da Biblioteca Central da Universidade Federal de Pernambuco, que objetiva ofertar um momento para discussão sobre a formação de leitores e de mediadores de leitura e propiciar vivências de incentivo ao gosto e hábito de ler. Em duas edições realizadas, constituiu-se uma atividade extensionista que envolveu múltiplos parceiros. Compreendendo um debate técnico, oficinas e vivências estruturadas a partir da definição dos temas, busca de parceiros, planejamento e gestão do evento, marketing e avaliação das atividades realizadas. Fundamenta-se na necessidade e importância da ação das universidades e suas bibliotecas no fomento da leitura como um ato prazeroso e essencial daqueles que vivem na sociedade da informação e do conhecimento. Obteve-se grande receptividade e a avaliação revelou ter superado as expectativas dos participantes e o acerto das estratégias adotadas nas duas edições.

PALAVRAS-CHAVE: Biblioteca universitária. Extensão universitária. Encantar. Leitura. Formação de leitores.

ABSTRACT: Reports the experience of project "Encantar" - Libraries, Reading and Story Telling Meeting, from the User Support Division of Pernambuco Federal University, that steers to offer a moment for discussions concerning to readers and reading mediators formation, providing experiences of incentive reading liking and habit. On two editions, consisted in an extensive activity, gathering several partners. Comprising a technical discussion, workshops, structured experiences from the definition of themes, partners seeking, planning, event management, marketing and activities assessment. Based on the need and importance of action in universities and its libraries, promoting reading as an essential and pleasant act, for those who live into the knowledge and information community. Great receptivity has been granted, and the evaluation has revealed expectations overcoming from participants, and the correct strategies carried on the first two editions.

KEYWORDS: College library. College extension. Encantar. Reading. Readers formation.

\footnotetext{
${ }^{1}$ Possui graduação em Biblioteconomia pela Universidade Federal de Pernambuco (1995). Especialista em Gerência de Sistemas de Informação pela FESP (2002). Email: susyleide@yahoo.com.br

${ }^{2}$ Bibliotecária especialista da Faculdade de Direito da Universidade Federal de Pernambuco. Email: marines.vidal@gmail.com

${ }^{3}$ Bibliotecária da Divisão de Apoio ao Usuário da Biblioteca Central da UFPE. Também faz parte da equipe de professores do Programa Manuel Bandeira de Formação de Leitores da Secretaria de Educação, Esporte e Lazer da Prefeitura de Recife. Email: karyna rocha@hotmail.com

${ }^{4}$ Bibliotecária especialista da Biblioteca Central da Universidade Federal de Pernambuco. Pós graduanda em Gestão da Informação em Arquivo. Email: shirlypimentel@hotmail.com

Submetido em: 18/09/2013-Aceito em: 24/06/2014.
} 


\section{INTRODUÇÃ̃}

As bibliotecas universitárias comumente promovem cursos. Ocasionalmente, outras atividades de extensão.

Aborda-se uma iniciativa da Divisão de Apoio ao Usuário (DAU) da Biblioteca Central (BC) da Universidade Federal de Pernambuco (UFPE), o projeto Encantar - Encontro de Bibliotecas, Leitura e Contação de Histórias, que visa o fomento da leitura.

Os objetivos deste relato de experiência são: divulgar o projeto Encantar e levantar discussão sobre a iniciativa da BC/UFPE de realizá-lo.

A seção dois aborda o vínculo entre a extensão e biblioteca universitária. Na terceira, tratam-se dos diversos sentidos do ato de ler e da leitura como uma forma de encantamento. Na seção quatro, apresentam-se os aspectos mais significativos das edições de 2011 e 2012 do Encantar e, então, as considerações finais.

\section{EXTENSÃO UNIVERSITÁRIA \& BIBLIOTECA UNIVERSITÁRIA: UM DIÁLOGO POSSÍveL}

A extensão universitária integra o tripé ensino, pesquisa e extensão, que norteia a atuação das universidades. Pode ser conceituada como atividade desenvolvida com o objetivo de aproximar a universidade da sociedade, para o compartilhamento dos conhecimentos e experiências mútuos. Por isso, é importante perceber a extensão como um dos pilares das instituições de ensino superior e, dessa forma, valorizar a realização de eventos que busquem a integração da comunidade universitária com a comunidade circunvizinha, como parte do fazer universitário.

Gonçalves et al. (2008, p. 3) afirmam que "a extensão universitária é considerada um intercâmbio entre a universidade e a sociedade, de forma a dialogar, partilhar e trocar saberes". Ela proporciona que a universidade, ambiente democrático e participativo, interaja principalmente com os grupos menos favorecidos e facilite o acesso ao conhecimento adquirido, baseado no ensino e na pesquisa científica, e ao oriundo das experiências desses grupos. 
As iniciativas de extensão podem contribuir para atenuar o desconforto que atinge as sociedades, provocado pelas rápidas mudanças que ocorrem no mundo. Transformações que modificam a forma de fazer, ensinar, aprender e investigar. Segundo Almeida (2007, p. 2), "esse fluxo de conhecimentos entre acadêmicos e comunidade acrescenta a ambos a produção de conhecimentos resultantes do confronto entre teoria e realidade social". Dessa forma, essa interação proporciona a criação de um ambiente criativo e inovador para a resolução de problemas sociais, dentre outros.

O paradigma tecnológico trouxe transformações profundas na sociedade. Aumentando as diferenças sociais, agravando a situação dos grupos menos favorecidos ao acesso a bens e serviços. Neste prisma, Almeida (2007, p. 2) comenta que a interação entre a universidade e a comunidade "é de suma importância" porque permite "socializar e democratizar o conhecimento, capaz de fazer surgir uma nova diretriz à universidade brasileira, e de contribuir significativamente para a mudança da sociedade como um todo".

Uma das funções da universidade é fazer desabrochar o pensamento crítico por meio da informação e do ensino adquiridos no âmbito da academia. Por muitos anos a universidade desempenhou, unicamente, o papel de transmitir o saber: o ensinar. Somente no século XIX é que a pesquisa dá sinal de existência e merece destaque no meio acadêmico, acontecendo então a chamada Primeira Revolução Acadêmica. Para Brisolla (1997, p. 187), a Segunda Revolução Acadêmica "é caracterizada pela agregação da função de desenvolvimento econômico regional e local, às já clássicas atividades de pesquisa e ensino desempenhadas pela universidade".

De qualquer forma, o mais significativo àquele tempo era a divulgação do conhecimento em eventos e periódicos, e pouco se valorizava a iniciativa de transferência do conhecimento gerado. Rodrigues Júnior (2000, p. 232) reafirma a atuação das universidades no desenvolvimento econômico regional e salienta o vínculo entre o financiamento público e a contribuição direta da universidade para a economia.

Cunha (2000, p. 5) afirma que “[...] a universidade atual pode ser considerada como um 'servidor' de conhecimentos que provê serviços e produtos, isto é, a criação, preservação e transmissão de conhecimentos sobre qualquer forma solicitada".

Diante das mudanças que a sociedade vivencia, as bibliotecas universitárias precisam repensar o seu papel junto às comunidades que atendem e que estão no seu entorno. Segundo Amorim (2012, p. 2), elas "ocupam o espaço de mediadoras do conhecimento e dos saberes 
[...]" e por isso não devem se afastar do ensino, pesquisa e extensão, mas criar oportunidades de participar de ações que permitam, ainda conforme Amorim (2012, p. 2), "dinamizar o acesso à informação, possibilitando o pleno exercício da cidadania e a inclusão social e cultural".

Com este pensamento, é necessário levar a biblioteca universitária para junto da sociedade e trazer a comunidade até ela, proporcionando práticas informacionais com projetos e ações extensionistas que ultrapassem os limites físicos da biblioteca e da universidade. Exercer a cidadania está relacionado aos caminhos que as bibliotecas estão tomando para aproximar-se da sociedade, diminuindo o vácuo ou os efeitos excludentes sentidos pela sociedade.

O I Encontro Nacional de Pró-Reitores de Extensão das Universidades, que aconteceu em 1987, estabeleceu as diretrizes e as bases conceituais vigentes, fazendo com que alguns profissionais da informação, que atuam nas bibliotecas universitárias, realizem, mesmo que de maneira incipiente, atividades de promoção da leitura, oficinas e palestras para as comunidades externas.

Para participar como elemento proativo deste contexto, a Biblioteca Central (BC) da UFPE, em outubro de 2011, realizou o Encantar, que passou a fazer parte de seu Plano de Ação. Em 2013, ocorrerá a terceira edição.

\section{SENTIDOS DA LEITURA}

Maria (2002, p. 51) ressalta as contribuições da leitura ao declarar que a:

Concepção de leitura que nasce no horizonte de um compromisso político: uma leitura que não apenas ofereça respostas ao homem sobre sua própria realidade, mas, que também o instigue a colocarem-se questões e o instrumente na busca de respostas e soluções; uma leitura que desinstale o homem da placidez e da acomodação e ao mesmo tempo seja capaz de torná-lo melhor. Melhor em sua relação com os outros, em sua relação com o meio, em sua relação consigo mesmo. Melhor no sentido de melhor praticar sua humanidade.

Fonseca (2007, p.70) afirma sobre a complexidade da leitura: há mais do que "ensina a psicolinguística experimental [...], que a reduz a simples resposta a um estímulo", ou a teoria da comunicação, que "a define como segunda etapa do processo emissão/recepção", ou ainda o marketing cultural, para qual "o ler é consumir um texto".

Explicita que ler vai muito além de simplesmente decifrar as palavras; é preciso entender o que está sendo lido e tornar as informações adquiridas em fator de transformação pessoal, 
social e política. Ao reafirmar a leitura como veículo de transformação social, Freire (2007, p.13) alerta que "estudar e ler não é um ato de consumir ideias, mas de criá-las e recriá-las". Afirma ainda que

o ato de ler não se esgota na decodificação pura da palavra escrita ou da linguagem escrita, mas que se antecipa e se alonga na inteligência do mundo. A leitura do mundo precede a leitura da palavra, daí que a posterior leitura desta não possa prescindir da continuidade da leitura daquele. (FREIRE, 2009, p. 11).

Atualmente, as questões relacionadas à leitura não são interesse somente de estudiosos. Em 2004, iniciou-se intensa mobilização em prol da leitura. O ano de 2005 foi intitulado o Ano Ibero-americano da Leitura. Governo, setor privado e o terceiro setor iniciaram ações de fomento para o livro e leitura. Em 2006, o Ministério da Cultura e o Ministério da Educação criaram o Plano Nacional do Livro e da Leitura - PNLL. E o que diz o PNLL (BRASIL, 2006, p.20) sobre a leitura?

A leitura e a escrita constituem elementos fundamentais para a construção de sociedades democráticas, baseadas na diversidade, na pluralidade e no exercício da cidadania; são direitos de todos, constituindo condição necessária para que possam exercer seus direitos fundamentais, viver uma vida digna e contribuir na construção de uma sociedade mais justa.

A concepção de leitura focalizada pelo Plano é aquela que ultrapassa o código da escrita alfabética e a mera capacidade de decifrar caracteres, percebendo-a como um processo complexo de compreensão e produção de sentidos, sujeito a variáveis, de ordem social, psicológica, fisiológica, linguística e outras; uma perspectiva mecanicista da leitura, que pretende reduzir o ato de ler a mera reprodução do que está no texto, tem sido um dos mais graves obstáculos para o desenvolvimento da leitura e da escrita. A leitura configura um ato criativo de construção de sentidos, realizado pelos leitores a partir de um texto criado por outro(s) sujeito(s).

\subsection{O Encantamento da Leitura}

A palavra encantamento significa: "ato ou efeito de encantar (-se). Sensação de deslumbramento, admiração, grande prazer que se tem como reação a alguma boa qualidade do que se vê, ouve, percebe". (HOUAISS, 2007, p. 1132). O encantamento remete à magia, a um feitiço, que deixa o indivíduo em estado absorto. Será que a leitura tem esse poder? Será que ela tira a pessoa de sua realidade e a envia ao mundo encantado? Será que o ser humano precisa deste encantamento? Por quê?

São tantas as indagações possíveis... Há teóricos (Solé, 1998; Zilberman, 1998; Lajolo, 2003 e Morais, 1996) que conceituam a leitura sob a perspectiva de deslumbramento, a leitura como necessidade básica do ser humano para encontrar respostas e encontrar-se como cidadão crítico.

Solé (1998, p. 90) ressalta que "ler é uma atividade voluntária e prazerosa". 
E ainda comenta que

A leitura "de verdade", aquela que realizamos os leitores experientes e que nos motiva, é a leitura na qual nós mesmos mandamos: relendo, parando para saboreá-la ou refletir sobre ela, pulando parágrafo...uma leitura íntima, e por isso, individual. (SOLÉ, 1998, p. 43).

Morais (1996, p. 12-13) reafirma Solé ao dizer que

Os prazeres da leitura são múltiplos. Lemos para saber compreender, para refletir. Lemos também pela beleza da linguagem, para nossa emoção, para nossa perturbação. Lemos para compartilhar. Lemos para sonhar e para aprender a sonhar Há várias maneiras de sonhar... A melhor maneira de começar a sonhar é por meio dos livros... aprender a dedicar-se totalmente à leitura [...].

A leitura humaniza o homem, torna seu olhar mais sensível para consigo mesmo, o outro e o mundo. Além disso, a leitura também proporciona prazer, deleite. Scliar (2008, p. 40) visualiza a leitura como uma casa com muitas portas, sendo a do prazer uma "das mais largas e acolhedoras" e destaca que

Leitura informa, leitura emociona, leitura é coisa prazerosa. Há um aspecto lúdico no ato de escrever, na escolha das palavras que construirão o nosso relato; e esse prazer de uma forma ou de outra chega ao leitor. (SCLIAR, 2008, p. 40).

É no âmbito acadêmico que se encontram a maioria dos futuros mediadores de leitura (pedagogos, bibliotecários, professores e escritores) que poderão despertar/incentiva o encantamento pela leitura. Os futuros mediadores já são encantados pela leitura?

\section{PROJETO ENCANTAR}

O Encantar - Encontro de Bibliotecas, Leitura e Contação de Histórias é uma realização das Bibliotecas Central e Setorial do Centro de Educação, em parceria com a Biblioteca Pública do Estado de Pernambuco, Pontos de Leitura e outras instituições.

Este evento objetiva a criação de um espaço, na UFPE, para discussão sobre formação de leitores e de mediadores de leitura. Constitui um momento de reflexão sobre as práticas e estratégias de incentivo ao gosto e ao hábito de ler, fomentando debates e propiciando vivências fundamentadas nos objetivos do PNLL.

O Encantar se estrutura a partir de três eixos: debate teórico (mesa redonda), formação de mediadores de leitura (oficinas) e vivências (maratona, exposição e biblioteca), nesta ordem. Seus objetivos específicos são: 
a) promover a discussão no âmbito das bibliotecas do Sistema Integrada de Bibliotecas(SIB) da UFPE sobre a acessibilidade à biblioteca e ao livro, considerando as estratégias de fomento à leitura;

b) discutir as estratégias de formação de leitores relacionadas com a contação de histórias;

c) abordar a importância das ilustrações nas obras infantis e da contação de histórias na formação do leitor;

d) realizar oficinas de contação de histórias, de ilustração e de normalização de livros, seguindo as normas da Associação Brasileira de Normas Técnicas (ABNT);

e) propiciar a oportunidade de vivenciar o uso de uma biblioteca infanto-juvenil às crianças e adolescentes participantes do Encantar;

f) promover uma maratona de contação de história, colocando em prática os conhecimentos adquiridos nas oficinas; e

g) expor as ilustrações resultantes das oficinas.

Seu público-alvo são os alunos dos cursos de Biblioteconomia, Letras e Pedagogia, professores, bibliotecários, arte-educadores e agentes de leitura. Pessoas que encontram na prática profissional o desafio da formação do gosto e do hábito de leitura.

As crianças e os adolescentes, principalmente, da rede pública de ensino, também são seus beneficiários ao participar de momentos lúdicos de despertamento da leitura, ato tão imprescindível para sua vida, como também vivenciar o uso de uma biblioteca infantojuvenil montada especificamente para o evento.

As estratégias a serem adotadas dividem-se em cinco eixos:

1. definição dos temas - em cada edição abordam-se novos temas;

2. busca por parceiros - procuram-se potenciais parceiros (bibliotecas, departamentos acadêmicos, estudantes universitários, professores, servidores públicos, empresas públicas e privadas e financiadores) para obter doação de recursos materiais e disponibilização do trabalho voluntário, bem como definem-se as contrapartidas;

3. planejamento e gerenciamento do evento - planejam-se as ações e a gestão dos recursos humanos e materiais, o fluxo de comunicação entre as equipes para o alcance efetivo dos objetivos; 
4. marketing - produzem-se os materiais de divulgação e de memória do evento (folders, cartazes, banners, faixas, filmagem e fotografia), utilizam-se os canais de comunicação da Universidade (boletim eletrônico, página do SIB/UFPE, rádio, televisão etc.); $\mathrm{e}$

5. avaliação - aplicam-se questionários para a avaliar a mesa redonda, as oficinas e a maratona.

Considera-se que a equipe ideal é composta de, no mínimo, cinco pessoas para a comissão do evento, duas para a logística, quatro bolsistas e vinte contadores de histórias. Tais quantidades são compatíveis com os dois turnos do evento (manhã e tarde).

\subsection{Encantar 2011 e 2012}

O primeiro Encontro teve como objetivo comemorar a Semana Nacional do Livro e da Biblioteca, bem como, formar multiplicadores na contação e ilustração de histórias visando a desenvolver e incentivar o gosto pela leitura.

As informações a ele pertinentes estão apresentadas no Quadro 1.

QUADRO 1 - Encantar 2011

\begin{tabular}{|c|c|}
\hline Período de Realização & 24 a 27 de outubro. \\
\hline Tema & Biblioteca, leitura e contação de história. \\
\hline Mesa redonda & Entre as páginas do livro, a palavra e a imagem. \\
\hline Oficinas & $\begin{array}{ll}\checkmark & \text { Ilustração de livros infantis. } \\
\checkmark & \text { Contar e encantar; e } \\
\checkmark & \text { Contar histórias, tecer sonhos: técnicas e alternativas } \\
\text { funcionais para a narrativa do encantamento. }\end{array}$ \\
\hline Vivências & $\begin{array}{ll}\checkmark & \text { Maratona de contação de histórias. } \\
\checkmark & \text { Uso da biblioteca Infantojuvenil. }\end{array}$ \\
\hline Equipe & 07 bibliotecários, 03 técnicos administrativos, 05 bolsistas. \\
\hline Exposição & Exposição de Ilustração. \\
\hline Participantes & 400 \\
\hline Parceiros & $\begin{array}{l}\text { Departamento de Ciência da Informação (DCI), Editora } \\
\text { Universitária da UFPE, Centro de Ciências Sociais Aplicadas }\end{array}$ \\
\hline
\end{tabular}


(CCSA), Biblioteca do Centro de Educação (CE), Biblioteca

Pública do Estado de Pernambuco (BPE), contadores de histórias,

Secretaria de Educação, Esportes e Lazer da Prefeitura da Cidade

do Recife, Ponto de Leitura de Paulista (PLP), Empresas Privadas

(Vitarella e Pipocas Venezas).

Fonte: Relatório do Encantar 2011

Supõe-se que a avaliação tão positiva apresentada na Tabela 1 evidencia:

$\checkmark \quad$ a superação das expectativas dos participantes;

$\checkmark \quad$ a vivência de uma experiência singular;

$\checkmark \quad$ o atendimento a lacunas sentidas em sua formação pelos mediadores de leitura;

$\mathrm{e}$

o entusiasmo da equipe e dos participantes em suas ações.

TABELA 1 - Avaliação do Encantar 2011

\begin{tabular}{lcccc}
\hline \multicolumn{1}{c}{ Avaliação } & \multicolumn{4}{c}{ Respostas (\%) } \\
\hline & Muito bom & Bom & Ruim & Péssimo \\
Conteúdo abordado & 100 & 0 & 0 & 0 \\
Tempo de duração do evento & 100 & 0 & 0 & 0 \\
Metodologia utilizada & 100 & 0 & 0 & 0 \\
Relevância do Encontro & 100 & 0 & 0 & 0 \\
\hline
\end{tabular}

Fonte: Relatório do Encantar 2011

Não foi possível realizar o Encantar 2012 na Semana Nacional do Livro e da Biblioteca em virtude da reforma nas instalações físicas da BC. Essa situação impediu a montagem da biblioteca infantojuvenil, bem como a realização da oficina e a exposição de ilustração de livros infantis. Consequentemente, houve redução da equipe, mas o número de participantes aumentou.

O objetivo do Encantar 2012 foi o mesmo da primeira edição.

No Quadro 2 encontram-se as informações referentes à segunda edição do Encontro. 
QUADRO 2 - Encantar 2012

17 a 20 de dezembro.

\begin{tabular}{ll}
\hline Temas & Biblioteca, leitura e contação de história. \\
Mesa redonda & No prazer de ler a descoberta do saber. \\
\hline Oficinas & Oficina de contação de história: inicio meio e fim \\
& Oficina de leitura e letramento: de dentro para fora \\
Vivências & Maratona de contação de histórias \\
\hline Equipe & 03 bibliotecários, 01 técnico-administrativo, 02 bolsistas \\
& Empresa Tapete Voador: atividades burocráticas. \\
\hline Participantes & 460 \\
Parceiros & DCI, Biblioteca do CE (ambos da UFPE), contadores de \\
história, BPE, PLP, Biblioteca Popular de Afogados e Casa \\
Amarela, Rede de Bibliotecas Comunitárias. Empresa Tapete \\
\end{tabular}

Fonte: Relatório do Encantar 2012

A empresa $\mathrm{O}$ Tapete Voador executou as atividades burocráticas do evento.

Julga-se que a avaliação mais uma vez tão positiva tenha ocorrido pelas mesmas razões apontadas para a ótima opinião dos participantes da edição anterior.

TABELA 2 - Avalição Encantar 2012

\begin{tabular}{lcccc}
\hline \multicolumn{1}{c}{ Avaliação } & \multicolumn{4}{c}{ Respostas (\%) } \\
\hline Muito bom & Bom & Ruim & Péssimo \\
Conteúdo abordado & 10 & 90 & 0 & 0 \\
Tempo de duração do evento & 100 & 0 & 0 & 0 \\
Metodologia utilizada & 100 & 0 & 0 & 0 \\
Relevância do Encontro & 100 & 0 & 0 & 0 \\
\hline
\end{tabular}

Fonte: Relatório do Encantar 2012 


\section{CONSIDERAÇõES FINAIS}

A leitura é uma das portas de acesso ao mundo. Ler não é apenas decifrar símbolos, mas, ressignificá-los. O leitor precisa captar a mensagem com ela dialogar e ser capaz de dar um sentido próprio ao que lhe foi transmitido.

Segundo Marques Neto (2010, p. 19), o "Brasil está apenas começando a se projetar como um país leitor e ainda precisará do incansável trabalho de muitos para atingir a dignidade que deve aos seus cidadãos”. A Universidade é uma das instituições responsáveis pela formação profissional destes "muitos" a que se refere o autor.

Rosa e Oddone (2006, p. 185) ressaltam que a maioria dos que ingressam na universidade não têm habilidades leitoras amadurecidas, fato "decorrente do enfoque da cultura pré-vestibular do ensino médio".

$\mathrm{Na}$ sociedade da informação o uso do aparato tecnológico exige o domínio da leitura, mas não como um ato mecânico. Retoma-se a afirmativa de Freire (2007, p. 13): "estudar e ler não é um ato de consumir ideias, mas de criá-las e recriá-las”.

Projetos como o Encantar possibilitam às bibliotecas cooperar nos esforços do incentivo ao gosto e hábito de leitura, contribuir na formação de profissionais mais capacitados a enfrentar as rápidas e constantes mudanças que ocorrem na sociedade de informação e do conhecimento e oferecer a adolescentes e crianças, principalmente da rede pública do ensino, vivências que propiciem a percepção da leitura como um ato de prazer e uma chave para penetrar em um mundo deslumbrante.

O êxito das duas edições do Encantar resultou em sua inclusão no plano de ação anual da BC.

Sugere-se o estudo pelas bibliotecas universitárias de oferta de ambiente físico para o estudo e leitura, uma vez que é comum às residências da maioria da população brasileira não haver espaço físico que propicie a leitura e estudo.

Almeja-se tornar o Encantar um projeto ligado à Pró-Reitoria de Extensão da UFPE, no sentido de viabilizar a captação de recursos necessários, e para que o mesmo permaneça como uma atividade extensionista regular, já que a formação de leitores e mediadores dever ser uma ação continuada.

O espaço acadêmico pode ser um celeiro riquíssimo para debates e reflexões acerca das problemáticas que envolvem a prática leitora, e porque não dizer, da própria sociedade, tornando-se laboratório para experiências e espaço privilegiado para a formação de mediadores de leitura. $\mathrm{O}$ caráter extensionista da universidade possibilita o diálogo entre a 
teoria e a prática, permitindo o que afirma Werthein (2008, p. 43) "a leitura e cidadania têm tudo a ver".

\section{REFERÊNCIAS}

ALMEIDA, Nayele de Freitas; GIROTO, Ana Paula Santana. Extensão universitária como diretriz da disseminação de conhecimento. Encontro de Iniciação Científica, v. 3, n.3, p.112, 2007. Disponível em: <

http://intertemas.unitoledo.br/revista/index.php/ETIC/article/viewArticle/1473 >. Acesso em: 04 mar. 2013.

AMORIM, Ana Neri Barreto de. Dinamização e ações culturais dos serviços e produtos informacionais da Biblioteca Central Prof. Antônio Martins Filho da Universidade Estadual do Ceará. In: SEMINÁRIO NACIONAL DE BIBLIOTECA UNIVERSITÁRIAS, 17., 2012, Gramado. Anais... Gramado, 2012. Disponível em:

<http://www.snbu2012.com.br/anais/pdf/4QHH.pdf >. Acesso em: 04 mar. 2013.

BRASIL. Ministério da Educação. Ministério da Cultura. Plano Nacional do Livro e Leitura. 2006. Disponível em: 〈http://www.oei.es/fomentolectura/pnll_brasil.pdf >. Acesso em: 20 mar. 2013.

BRISOLLA, Sandra et al . As relações universidade-empresa-governo: um estudo sobre a Universidade Estadual de Campinas (Unicamp). Educação \& Sociedade, v.18, n. 61, dez. 1997.

CUNHA, Murilo Bastos. Construindo o futuro: a biblioteca universitária em 2010. Ciência da Informação, v. 29, n. 1, p. 71-79, jan./abr. 2000.

ENCONTRO DE PRÓ-REITORES DE EXTENSÃO DAS UNIVERSIDADES PÚBLICAS BRASILEIRAS, 1., Brasília. Conceito de extensão, institucionalização e financiamento. Brasília: Universidade de Brasília, 1987. Disponível em:

<http://www.renex.org.br/documentos/Encontro-Nacional/1987-I-Encontro-Nacional-doFORPROEX.pdf>. Acesso em: 04 mar. 2013.

FONSECA, Edson Nery da. Introdução à biblioteconomia. 2. ed. Brasília: Briquet de Lemos, 2007. 152p.

FREIRE, Paulo. Ação cultural para a liberdade e outros ensaios. 12. ed. Rio de Janeiro: Paz e Terra, 2007. 176p.

FREIRE, Paulo. A importância do ato de ler: em três artigos que se completam. 50. ed. São Paulo: Cortez, 2009. 87p.

GONÇALVES, M. F. et al. Projeto de extensão no Sistema de Bibliotecas da UNEB: o início de uma itinerância. In: SEMINÁRIO NACIONAL DE BIBLIOTECA UNIVERSITÁRIAS, 
15., 2008, São Paulo. Anais... São Paulo, 2008. Disponível em:

<http://www.sbu.unicamp.br/snbu2008/anais/site/pdfs/2616.pdf>. Acesso em: 04 mar. 2013.

HOUAISS, Antonio et al. Dicionário Houaiss da língua portuguesa. Rio de Janeiro, 2007. 2922p.

LAJOLO, Marisa; ZILBERMAN, Regina. A formação da leitura no Brasil. 3. ed. São Paulo: Ática, 2003. 374p.

MARIA, Luzia de. Leitura e colheita: livros, leitura e formação de leitores. Petrópolis: Vozes, 2002. 174p.

MARQUES NETO, José Castilho. Plano Nacional do Livro e da Leitura: os primeiros quatro anos e o futuro. In: BRASIL. Ministério da Educação. Ministério da Cultura. Plano Nacional do Livro e Leitura: Estado e sociedade atuando pelo desenvolvimento da leitura no Brasil, 2010. 47 p. Disponível em: < http://www2.cultura.gov.br/cnpc/wpcontent/uploads/2011/07/plano-nacional-do-livro-e-leitura1.pdf >. Acesso em: 20 mar. 2013.

MORAIS, José. A arte de ler. São Paulo: Editora da Universidade Estadual Paulista, 1996. $327 \mathrm{p}$.

RODRIGUES JÚNIOR, José Maciel et al. Produção do conhecimento tecnológico da UFMG. Perspectiva em Ciência da Informação, Belo Horizonte, v. 5, n. 2, p. 231-242, jul./dez. 2000 .

ROSA, Flávia Goullart Mota Garcia; ODDONE, Nanci. Políticas públicas para o livro, leitura e biblioteca. Ciência da Informação, v.35, p. 183-193, set./dez. 2006.

SCLIAR, Moacyr. O valor simbólico da leitura. In: AMORIM, Galeno. Retratos da leitura no Brasil. São Paulo: Imprensa Oficial: Instituto Pró-livro, 2008. p. 31- 40.

SOLÉ, Isabel. Estratégias de leitura. 6. ed. Porto Alegre: Artmed, 1998. 194p.

WERTHEIN, Jorge. Leitura e cidadania. In: AMORIM, Galeno. Retratos da leitura no Brasil. São Paulo: Imprensa Oficial: Instituto Pró-livro, 2008. p. 41-48.

ZILBERMAN, Regina; SILVA, Ezequiel Theodoro da Silva (Org.) Leitura: perspectivas interdisciplinares. 4. ed. São Paulo: Ática, 1998. 115p.

\section{Como citar este artigo:}

BRITO, Susyleide Gomes de; VIDAL, Maria Marinês Gomes; TAVARES, Karyna da Rocha; VIEIRA, Shirly Pimentel. Encantar - Encontro de Bibliotecas, Leitura e Contação de Histórias. Rev. digit. bibliotecon. cienc. inf., Campinas, SP, v.12, n.3, p.157-170, set/dez. 2014. ISSN 1678-765X. Disponivel em:

<http://www.sbu.unicamp.br/seer/ojs/index.php/rbci>. Acesso em: 31 ago. 2014. 